\title{
Research on the System of Indirect Patent Infringement -- Take "3D printing" as an example
}

\author{
Zhou Zhi-de $\mathrm{a}^{*}$, Yu Shan-shan ${ }^{\mathrm{b}}$ \\ School of Intellectual Property, GuiLin University of Electronic Science and Technology, GuiLin 541004, China \\ $a^{*} 854167177 @ q q . c o m$ \\ b645387486@qq.com
}

\begin{abstract}
This paper takes the indirect infringement of patent involved in the provision of 3D printing by University Library as an example, starting from the current situation of patent infringement legislation, the recognition of indirect infringement of patent, and the relationship between direct infringement, analyzes the impact of the development of "3D printing" new technology on the patent infringement system, and studies the legitimacy of establishing the patent indirect infringement system. This paper discusses the behavior of providing and disseminating CAD documents of patent products in 3D printing, which helps or entices others to download the documents and print the patent products accordingly. It is an indirect infringement of patent, and puts forward suggestions and measures to prevent indirect infringement of 3D printing patent.
\end{abstract}

Keywords: "3D printing", patent, indirect infringement, legitimacy

\section{专利间接侵权制度研究一以 “3D 打印”为例 \\ 周治德 $\mathrm{a}^{*}$, 禹姗姗}

桂林电子科技大学 知识产权学院, 广西, 桂林, 541004

a*854167177@qq.com

b645387486@qq.com

\section{摘要}

本文以高校图书馆提供3D打印行为涉及专利间接侵权为例, 从专利侵权立法现状、专利间接侵权认定, 与直接侵权行为的关系入手，分析“3D打印”新技术发展对专利侵权制度的冲击，研究建立专利间接侵 权制度的正当性。探讨3D打印中提供、传播专利产品 CAD 文档的行为, 帮助或引诱了他人下载该文档 并据此打印专利产品，属于专利间接侵权行为，提出防范3D打印专利间接侵权的建议与措施。

关键词: “3D 打印”，专利，间接侵权，正当性

\section{1. 前言}

最近出现有关高校图书馆提供 “3D打印”服务涉 嫌间接侵权的报道, 指出提供打印设备、协助完成打印 的行为, 构成了用户 $3 \mathrm{D}$ 打印行为的帮助行为, 如果用户 的打印行为存在侵犯知识产权的情形, 则高校图书馆将 面临间接侵权和承担连带责任的风险。引发了新技术3D 打印对知识产权制度的冲击, 有必要研究3D打印对专利 间接侵权制度的思考。

新技术3D打印对知识产权的保护产生冲击, “3D打 印” 是一种以数字模型文件为基础, 实际上是一个再制 造过程, 未经许可再制造他人享有知识产权的产品, 存 在侵权的风险。在利用3D打印技术打印的物体为专利产
品时, 未经许可, 则3D打印有侵犯专利权的风险; 在3D 打印中, 在物品上打印使用与他人的注册商标相同或近 似的标识，存在侵犯商标权的风险 ${ }^{[1]}$ 。随着3D打印技术 快速发展, 提供3D打印设备、提供3D打印专利产品CAD模 型, 以及提供3D打印数据共享平台的运营商都可能成为 专利间接侵权的主体。基于目前3D打印行为的特点, 按 照现行间接侵权构成原理，3D打印中提供、传播专利产 品 $\mathrm{CAD}$ 文档的行为虽然不构成专利直接侵权, 但其行为 帮助或引诱了他人下载该文档, 并利用该文档用3D打印 专利产品, 该行为是以帮助、诱导为特征的间接侵权行 为; 3D打印设备提供者也涉及间接侵权, 那么高校图书 馆提供3D打印服务有可能涉及专利间接侵权和赔偿损 失的琶䢟境界。 


\section{2. 专利间接侵权制度探讨}

\section{1 专利间接侵权与专利法侵权判定冲突}

针对3D打印专利侵权分析, 国内专利法的规定如下: 我国《专利法》2008版本第十一条规定了专利权的独占 性, 第五十九条规定了专利权的保护范围, 第六十条规 定了专利的专有权, 未经专利权人许可, 实施其专利, 即侵犯其专利权。专利法第七十条规定了主观目的, 为 生产经营目的使用、许诺销售或者销售等行为构成侵权, “以生产经营为目的” 构成专利侵权要件。2009司法解 释第二条, 人民法院应当根据权利要求的记载, 结合本 领域普通技术人员阅读说明书及附图后对权利要求的 理解, 确定专利法第五十九条第一款规定的权利要求的 内容, 实行周边限定-折衷-中心限定程序。在专利侵权 判定时, 首要原则是全面覆盖原则, 技术特征全面覆盖 比对后有两情况，一种是全部技术特征完全相同；另一 种是包含专利权利要求中记载的全部技术特征, 并且还 包含有其他技术特征; 这两种情况都视为侵犯专利权。 如果指被控侵权产品或者方法的技术特征比专利权利 要求中记载的全部技术特征少, 需要再适用等同原则。 2009司法解释第七条第二款规定, 被诉侵权技术方案包 含与权利要求记载的全部技术特征相同或者等同的技 术特征的，人民法院应当认定其落入专利权的保护范围; 被诉侵权技术方案的技术特征与权利要求记载的全部 技术特征相比, 缺少权利要求记载的一个以上的技术特 征, 或者有一个以上技术特征不相同也不等同的, 人民 法院应当认定其没有落入专利权的保护范围。等同侵权 判断中, 只能将被诉侵权产品的技术特征与专利技术方 案的对应技术特征相对比, 或者将被诉侵权产品与专利 字面技术方案进行比对, 是一对一而不是一对多的比对, 这样缺少要件组成的技术方案并未经过审查和授权, 明 显扩大了保护范围。综上所述，专利等同原则并不能挑 战或者突破全面覆盖原则。我国最近的司法政策也提出 了谨慎等同的原则, 给予等同原则以合理限制。按照上 述专利侵权判定原则适用, 提供3D打印设备的高校没有 全部实施专利权利要求书中的所有技术特征, 也不属于 等同侵权情形，是属于没有直接侵权专利权的情形。

间接侵权是与直接侵权相比较而言的, 是指以间接 方式侵害他人的人身、财产及其他合法权益并依法应当 承担民事责任的行为。我国法律中还没有间接侵权的直 接规定, 在司法实务中按共同侵权情况处理。《民法通 则》第 130 条规定, “二人以上共同侵权造成他人损害的, 应当承担连带责任” ; 《最高人民法院关于贯彻执行<中 华人民共和国民法通则 $>$ 若干问题的意见 (试行) 》第 148 条规定, “教唆、帮助他人实施侵权行为的人, 为共同 侵权人, 应当承担连带民事责任”。如果专利间接侵权 也进入专利法, 那么提供3D打印设备, 或者出售专利产 品, 或者用于使用专利方法的设备的一个主要零件, 只 要明知道这个主要零件是为了侵犯专利权而特别制造 的就构成侵权, 或者是引诱和教唆他人侵犯专利权都视 为侵犯专利权, 这种间接侵权判定思路与专利法侵权判
定思路产生冲突。在专利司法中，等同原则适用都要慎 用, 还要用抗辩原则、禁止反悔原则和捐赠原则来约束 等同原则，防止专利权保护范围扩大；如果引入专利间 接侵权原则, 侵犯权利要求书中部分技术特征、甚至引 诱和教唆他人侵犯专利权都有可能侵犯专利权，与《专 利法》第五十九条规定自相矛盾, 在专利实务操作时也 不知如何具体操作, 适用稍有不当, 就会妨害社会公共 利益。因此，现有《专利法》里面没有间接侵权条款。

\section{2 间接侵权立法分析}

关于间接侵权，不同的国家有不同的法律法规。美 国专利法第271（c）条规定：“任何人出售专利产品或 者用于使用专利方法的设备的一个主要组成零件, 明知 道这个组成零件是为了侵犯专利权而特别制造的, 不具 备除了侵犯专利权以外的其他用途, 他就负有共同侵权 的法律责任。” 英国专利法第60条 (2) 规定, 在专利权 的有效期间内，任何第三人未经专利权人的同意，在联 合王国向不属于被许可人或者无权实施专利发明的人， 提供或表示愿意提供任何有关发明的关键组成部分，而 使发明得到实施的，如果该人明知或者应知所提供的关 键组成部分适于并且旨在用于发明在联合王国实施，则 同样属于侵犯了该发明的专利权。德国专利法第 10 条规 定: 专利权的效力还在于禁止任何第三人未经专利权人 的许可，向无权使用专利发明的人提供涉及专利发明基 本要素的手段, 致使后者在本法有效地域范围内销售或 供应本发明。如果该第三人知道或者显然应当知道所述 的手段适于并且专门用于实施发明专利的话。

与我国相比，虽然我国《专利法》尚未明确规定专 利间接侵权，但是司法实践中一般根据上述规定追究诱 导者、帮助者的共同侵权责任。然而, 由于适用标准不 统一, 不同司法机关在共同侵权的表现形式及构成要件 上理解相异, 导致法律适用上缺乏可预见性。2013年9月 4 日北京高院发布的《专利侵权判定指南》在法律缺位的 现状下又采取了谨慎的态度, 改变了这一做法, 不再采 用 “间接侵权” 这一法律概念, 将间接侵权行为统一纳 入 “共同侵权行为”。2016年最高人民法院在《关于审 理侵犯专利权纠纷案件应用法律若干问题的解释 (二) 》 第二十一条新增了专利帮助侵权的规定, 这是目前我国 有关专利间接侵权的位阶最高的法律规定。第四次修改 的《专利法送审稿》和《司法解释 (二) 》主要是基于 电子商务的发展, 并未充分考虑到3D打印的特点, 有关 专利间接侵权的相关规定还局限于《侵权责任法》有关

“共同侵权” 的框架内且适用范围较小。因此, 有必要 澄清间接侵权与共同侵权的不同, 明确专利间接侵权的 适用条件和程序。

\section{3 建独立的专利间接侵权制度的正当性分 析}

对于是否应该构建独立于共同侵权框架的专利间 
接侵权制度，需要从专利法利益平衡角度，或者专利制 度成本角度来考虑。随着人工智能等高新技术的发展, 比如3D打印新技术的发展, 间接侵权形式发生很大的变 化, 出现了很多新情况, 间接侵权与传统的共同侵权理 论有本质的区别。

\section{3. 1 共同侵权理论无法解决专利间接侵权 问题}

第一，从侵权行为构成上看，3D打印在主观方面、 客观行为、损害结果与共同侵权均有不同。在主观方面, 共同侵权人可以是共同过失; 间接侵权行为人则只能是 故意或明知, 而3D打印设备提供者对侵权行为可能不知 情。在客观行为方面, 共同侵权的行为具有一致性、关 联性和连接性; 3D打印设备提供者与3D打印执行者的行 为是完全独立, 没有关联性, 间接侵权与直接侵权人行 为相互独立。在损害结果方面, 共同侵权的损害结果不 可分割, 是统一结果; 帮助、诱导多个直接侵权行为, 则可能分别产生多个损害结果, 提供3D打印设备的人或 单位与 $3 \mathrm{D}$ 打印执行者所造成的损害结果没有直接因果 关系, 间接侵权损害结果可以分开, 互不影响。第二, 从 “意思导向” 来看, 3D打印设备提供者与3D打印执行 者是无意思联络, 有别于共同侵权的意思联络。第三, 专利间接侵权和共同侵权源于不同的分类标准。共同侵 权制度旨在为多数人参与的侵权行为寻找救济途径, 而 间接侵权制度主要涉及知识产权受保护的程度。共同侵 权制度无法充分反映知识产权的公共政策属性, 无法适 用于单独存在的间接侵权情形，在适用上具有不确定性， 二者侧重点有所不同。第四, 责任承担方式不同。共同 侵权行为人之间按过错程度不同承担连带责任; 而3D打 印设备提供者要独立承担责任, 即专利间接侵权中, 由 被控专利间接侵权人独立承担责任。第四次《专利法送 审稿》提出, 在专利间接侵权成立的情况下, 由被控专 利间接侵权人和直接侵权人承担连带责任, 这种方式还 是属于共同侵权的责任承担方式。第五, 诉讼模式不同。 共同侵权属于必要共同诉讼, 所有侵权行为人需合并审 理。而专利间接侵权诉讼中, 权利人可以自由选择对象, 尤其当直接侵权人不易查明时, 可以直接起诉间接侵权 人。

\section{3.2 构建独立的专利间接侵权制度的必要 性}

3D打印技术发展对间接侵权制度起到促进作用, 建 立专利间接侵权制度的是知识产权制度发展的趋势。

一是赋予产品的设计图提供者和网络服务提供商 “守门人” 的地位。随着3D 打印时代的到来, 普通消费 者通过3D打印, 不需要借助生产和销售这些传统产业的 中间环节, 可以变成直接侵权行为人。在这种情况下, 直接侵权的案件具有范围广、分散度高、维权成本高、 取证难度大、单笔侵权行为损害赔偿数额低等问题和特
点。如果直接追究3D打印设计文档的传播者和销售者、 3D打印设备提供者、以及网络平台运营商的间接侵权责 任, 在司法实务操作上更为可行, 专利产品的传统的生 产商和销售商不能再胜任 “守门人” 的角色。

二是专利间接侵权制度的确立可以重新平衡专利 权人和社会公共利益。在3D打印时代, 与传统制造业生 产模式不同，人人都可成为使用者兼制造者。在专利维 权时, 权利人追究分散的个体的侵权责任不经济, 难度 很大。专利间接侵权制度的确立可以重新平衡专利权人 和社会公共利益, 增加途径有效保护权利人的合法权益。 因此，专利间接侵权制度不仅不会损害社会公共利益， 反而会在专利权人与社会公共利益之间寻找到新的结 合点。美国专利法的变迁史也表明，专利间接侵权制度 的优势在于弥补起诉直接侵权人成本过高、专利权人难 以得到有效救济的不足。

三是专利间接侵权制度赋予权利人自由选择起诉 对象的权利。当直接侵权人不易查明, 或者非常分散时, 可以直接起诉间接侵权人。高校图书馆提供3D打印设备, 当学生利用3D打印设备涉嫌侵权时, 去哪里人可以直接 起诉高校图书馆。在“搜狗诉百度专利侵权”系列案中, 搜狗起诉百度的百度输入法产品侵犯其方法专利权, 直 接侵权人是百度输入法的用户, 按照以生产经营为目的, 用户构成直接侵权。但是用户数量多、分布广、维权成 本高, 搜狗基于百度向用户提供百度输入法必然导致用 户侵犯搜狗专利权, 主张百度构成间接侵权, 这样便于 有效维权。但是, 如果根据北京高院的《当前知识产权 审判中需要注意的若干法律问题》的规定, 在没有在先 裁判认定直接侵权成立的情况下，搜狗不将直接侵权人 列为共同被告, 那么便无法将间接侵权人百度列为被告。

四是专利间接侵权在其他国家专利法中已经存在。 从比较法视角来看, 大陆法系国家, 比如德国、日本和 韩国等，在民法中规定了“共同侵权”，同时在专利法 中规定了 “间接侵权” ，说明共同侵权和间接侵权两种 制度可以并存。3D打印模式下专利侵权呈现出 “版权化” 趋势, 面对专利侵权的 “新模式” , 有必要建立独立于 共同侵权的专利间接侵权制度。

\section{3. 专利间接侵权认定与直接侵权行为的关系}

\section{1 “从属说”与 “独立说”之争}

独立说的目的在于更好地保护专利权人的利益, 认 为间接侵权行为不以直接侵权的发生为必要构成条件。 从属说主张, 为平衡社会公益和专利权人的利益, 即使 在3D打印技术下也要以直接侵权的存在为间接侵权的 前提。在主张专利间接侵权的权利人要举证证明有直接 侵权行为的存在或者有直接侵权的威胁、损害后果及二 者间的因果关系。适用该理论不要求专利权人证明直接 侵权行为实际已经发生, 只需要证明消费者在购买相关 产品后会按照被控侵权人的明示或暗示侵害专利人的 权利, 降低了专利权人的直接侵权举证责任。3D 打印 
背景下专利间接侵权宜采 “独立说” 间接侵权行为诱导 或帮助了直接侵权行为, 或者扩大了直接侵权的损害后 果。在美国侵权成文法和司法判例中, 采取 “从属说” 但专利直接侵权认定较为容易, 并未把 “为个人目的实 施” 视为专利侵权的例外, 并且也不要求直接侵权行为 发生在国内。而我国专利法将非生产经营为目的的专利 实施视为合理使用, 所以个人用户基于个人消费目的进 行的3D 打印行为就不能构成专利侵权。这样就无法追 究CAD文件制作者、销售者和传播者的共同侵权责任。

\section{2 采取 “独立说” 优于 “从属说”}

首先是采取独立说能减轻专利权人的举证成本。在 3D打印技术改变传统制造业的背景下，是否 “以生产经 营为目的” 的界限难以确定, 直接侵权行为难以构成, 以此为前提的间接侵权行为就成了无源之水。即使不以 “生产经营目的” 作为专利直接侵权的构成要件, 在 3D 打印背景下, 擅自通过网络等途径提供或传播专利产品 $\mathrm{CAD}$ 文档的行为本身, 极易诱发或帮助专利直接侵权行 为。若专利间接侵权责任构成以直接侵权的发生为前提, 专利权人因举证成本过高而无法追究间接侵权人的法 律责任。第二是采用独立说能更好地保护专利权人的利 益。因为认为间接侵权行为不以直接侵权的发生为必要 构成条件, 可以节省直接侵权举证的成本, 能更好地保 护专利权人的利益。第三是独立说符合 “事前防范” 的 专利法的理念。从历次专利法的修改进程来看, 体现了 从事后救济到事前防范的价值取向的转变。比如, 我国 专利法经第二次修改，给专利权人新增了“许诺销售权”, 目的在于把专利侵权消除在萌芽状态或实质侵权之前。 通过对专利间接侵权行为单独规制, 能有效防范直接侵 权行为, 体现了 “事前防范” 的专利保护理念。第四是 考察其他国家立法和司法实践, 专利间接侵权成立要件 的规定并不都以专利直接侵权为前提条件。如德国专利 法规定, 因第三人提供 “与发明的主要要素相联系的工 具” 就会提高直接专利侵权发生的可能性, 因而, 专利 间接侵权责任的发生、承担是独立的, 不以直接侵权为 成立要件。在日本, 目前有关间接侵权的构成也以 “独 立论” 为主流。在日本 “面包机案” 中, 虽然涉嫌侵权 的面包机的使用者多为非以经营为目的的普通家庭, 但 是法院最终认定间接侵权成立。

\section{4. 思考与建议}

\section{1 提供、传播 $C A D$ 文档行为的专利间接侵 权认定}

在3D 打印过程中, 提供、传播 $\mathrm{CAD}$ 文档的行为本 身没有侵犯专利权, 专利权人无法通过援引《侵权责任 法》相关条款维护权益; 但行为人的提供行为、传播行 为可能符合专利间接侵权的构成要件。在具体适用过程
中，提供、传播 $\mathrm{CAD}$ 文档的行为因 $\mathrm{CAD}$ 文档的性质不 明确而难以被认为构成帮助侵权, 行为人提供、传播 $C A D$ 文档的行为在主观上是否存在知道专利权存在的

“明知”，专利权人也难以举证，从而导致相关行为适 用专利间接侵权的障碍。在3D打印的背景下, 为更好地 应对3D打印给专利制度带来的挑战，专利间接侵权的认 定应该不以直接侵权为前提。为解决3D打印中适用间接 侵权制度的障碍, 应将CAD文档认定为“专门用于实施专 利的物品” ，在专利领域适用 “通知-删除” 规则, 并完 善相应的配套条件, 在3D打印背景下允许专利权人做出 关于专利间接侵权的通知。

\section{2 “为生产经营目的” 专利侵权主观目的 判定}

现代科技正在飞速发展，面对3D打印产业的蓬勃发 展，可以预测，3D打印在接下来的一段时间后将会以更 实惠、迅速、智能的态势融入人们的日常生活。3D打印 技术的萌芽到实现普及的过程，应该是一个法律制度与 技术发展相互促进的过程，专利制度应该适时地应对挑 战作出相应地调整, 实现维护专利权人利益的同时, 促 进这一新兴技术的发展。新型技术的发展, 或者说3D打 印技术的发展具有强大的生命力, 为了实现技术发展与 专利制度匹配, 预防侵犯专利权, 专利制度也要与时俱 进。随着3D打印技术的发展, 要逐步取消 “为生产经营 目的” 这一专利侵权判定要件的必要性, 3D打印中的专 利间接侵权判定应不以构成专利直接侵权为前提, CAD 文档应当被认定为 “专门用于实施专利的物品” 以及引 入 “通知一删除” 规则。在 “产品价值”、“使用程度” 缺乏清晰的界定, 有待后续进一步深入研究。

\section{5. 结语}

随着3D打印等新技术的快速发展, 建立专利间接侵 权制度被提上了议题。我国《司法解释（二）》第一次 正式规定专利间接侵权责任, 但还是以共同侵权框架为 基础, 实质上采纳的是间接侵权从属说。反观美国、德 国、日本等国, 如果行为人将产品提供给了他人, 但是 他人还未实施直接侵权行为, 或者其行为不构成专利侵 权, 这类行为均构成帮助侵权行为。因此, 我国应借鉴 其他国家专利法的专利间接侵权规定, 采取 “独立说”, 不以专利直接侵权行为的发生为认定专利间接侵权的 前提，也不与直接侵权人共同承担连带侵权责任，构建 独立于共同侵权框架外的专利间接侵权制度，强化对间 接专利侵权者的惩罚力度, 这样才有利于应对3D打印等 新技术高速发展背景下专利间接侵权行为限制, 为以后 专利间接侵权制度写进专利法打下基础。 


\section{基金项目}

广西科技发展战略研究专项 “科技立项与 专利代理制度研究” (桂科 ZL18077014), 广西 教改项目 (2018JGB195)

\section{References}

[1] Tian Lipu. (1996)Research on Some Basic Problems in Patent Protection and Patent Infringement.J .China Patent and Trademark, 3:10-26.

[2] Chen Chao. (2020) Analysis of Indirect Patent Infringement from the Perspective of 3D Printing Technology. J. Rule of Law and Society, 1:46-48.

[3] Ma Qiufen. (2018) Development of 3D Printing Industry and Reform of Patent System J. Electronic Intellectual Property,7:85-91.

[4] Luo Jiao. (2018) Intellectual Property risk of "3D printing" Service and its Countermeasures. J. Library Construction, 9:36-40. 